\title{
Graphical determination of approximate valence force constants of $C_{30}$-molecules
}

\author{
W. M. A. Smrt and J. H. van der MaAs \\ Laboratory of Analytical Chemistry, State University Utrecht, The Netherlands
}

(Received 13 December 1966)

\begin{abstract}
It is shown that by plotting $f, d$-curves from frequency formulae, derived by Lechner for symmetric top molecules, force constant values can be obtained for the stretching and bending modes, which give a reasonably good fit of the observed frequencies. Simplification of the procedure results from using an apex angle $\alpha$ as calculated from the frequency formulae.
\end{abstract}

MANY authors have reported on force constants for $C_{3 v}$-molecules [1-6], using a valence-type potential function with two constants. In many cases the calculated frequencies proved to be in poor agreement with the observed ones.

A better fit of the observed fundamentals is obtained if the two force constants ( $f$ and $d$ for the stretching and bending modes respectively) are determined graphically as follows. By substituting the data for the four normal frequencies in the formulae of LeChNer [7], two linear and two hyperbolic equations result. The latter are used to calculate the angle $\beta$ between the altitude and the edge of the pyramid. The angle $\beta$ is related to the apex angle $\alpha$ by

$$
\sin \beta=\frac{2}{\sqrt{3}} \sin \frac{1}{2} \alpha
$$

The calculated $\beta$-values do not always agree with the apex angle known from other evidence, but as is well known, force constants are rather insensitive to variation of the apex angle [1]. Using these $\beta$-values the two hyperbolic curves necessarily coincide. Values for $f$ and $d$ are found from the intersection of the hyperbolic curve and the bisectrix of the angle between the lines obtained from the two linear equations. (There may be two intersections, only one has physical meaning.) (See Figs. 1 and 2.)

The procedure as outlined above has been checked for a number of compounds (See Table 1). All molecules are considered to be four-mass models, consisting of a

[1] J. B. Howard, and E. Bright Wilson, Jr., J. Chem. Phys. 2, 630 (1934).

[2] J. B. Howard, J. Chem. Phys. 3, 207 (1935).

[3] J. T. Edsall, J. Chem. Phys. 5, 225 (1937).

[4] E. J. Rosensaum, D. J. Rubin and C. R. Sandberg, J. Chem. Phys. 8, 366 (1940).

[5] K. W. F. Kohlrausor, Der Smekal-Raman-Effekt, Ergänzungsband 1931-1937, p. 144. Springer (1938).

[6] G. Hrezzerg, Molecular Spectra and Molecular Structure, II. Infrared and Raman Spectra of Polyatomic Molecules, 3rd Edition, p. 177. Van Nostrand (1947).

[7] F. LECHNER, Wien Ber. 141, 633 (1932). 
vertex atom $\mathrm{Y}(\mathrm{Y}=\mathrm{N}, \mathrm{P}, \mathrm{As}, \mathrm{Sb}, \mathrm{Bi})$ and three equal corner masses $\mathrm{X}(\mathrm{X}=$ hydrogen, halogen, methyl, and ethynyl). As can be seen the calculated frequencies are in good agreement with the observed ones. We checked the insensitivity of force constants to variation of the apex angle for some molecules (See Table 2 ). The $\alpha$-values used are taken from the references $[1-6,8-12]$ or are assumed. The force constants computed

Table 1. Normal frequencies $\omega$ in $\mathrm{cm}^{-1}$. For each substance: first row: observed

frequencies, second row: calculated frequencies. Force constants $f$ and $d$ in mdyn $/ \AA$. ( ) uncertain, see Ref. [16]

\begin{tabular}{|c|c|c|c|c|c|c|c|c|}
\hline \multirow[b]{2}{*}{ Substance } & \multicolumn{4}{|c|}{ Normal frequencies } & \multirow{2}{*}{$\begin{array}{c}\angle \mathrm{XYX} \\
\text { calc. }\end{array}$} & \multicolumn{2}{|c|}{ Forco const. } & \multirow{2}{*}{$\begin{array}{l}\text { References } \\
\text { for } \omega \text {-values }\end{array}$} \\
\hline & $\omega_{1}$ & $\omega_{2}$ & $\omega_{3}$ & $\omega_{4}$ & & & & \\
\hline \multirow[t]{2}{*}{$\mathrm{PH}_{3}$} & $2322 \cdot 9$ & $992 \cdot 0$ & $2327 \cdot 7$ & $1122 \cdot 4$ & $98^{\circ} 48^{\prime}$ & $3 \cdot 11$ & 0.332 & [12] \\
\hline & 2313 & 996 & 2338 & 1117 & & & & \\
\hline \multirow[t]{2}{*}{$\mathrm{PF}_{3}$} & 892 & 487 & $\mathbf{8 6 0}$ & 344 & $78^{\circ} 37^{\prime}$ & $4 \cdot 90$ & $0 \cdot 722$ & {$[5,6,11,13]$} \\
\hline & 953 & 456 & 816 & 363 & & & & \\
\hline \multirow{2}{*}{$\mathrm{PCl}_{3}$} & 510 & 257 & 480 & 190 & $85^{\circ} 45^{\prime}$ & $2 \cdot 01$ & $0 \cdot 389$ & {$[1,5,6,14]$} \\
\hline & 538 & 244 & 458 & 205 & & & & \\
\hline \multirow{2}{*}{$\mathrm{AsCl}_{3}$} & 410 & 193 & 370 & 159 & $82^{\circ} 36^{\prime}$ & $2 \cdot 03$ & $0 \cdot 248$ & {$[1,5,6,14]$} \\
\hline & 408 & 194 & 373 & 158 & & & & \\
\hline \multirow[t]{2}{*}{$\mathrm{N}\left(\mathrm{CH}_{3}\right)_{3}$} & 827 & 365 & 1036 & 423 & $109^{\circ} 2 \theta^{\prime}$ & $3 \cdot 82$ & $0 \cdot 437$ & {$[3,4]$} \\
\hline & 799 & 377.5 & 1073 & 408 & & & & \\
\hline \multirow{2}{*}{$\mathrm{P}\left(\mathrm{CH}_{3}\right)_{3}$} & 653 & 263 & 708 & 305 & $105^{\circ} 39^{\prime}$ & $2 \cdot 83$ & $0 \cdot 263$ & {$[4,15]$} \\
\hline & 661 & 260 & 730 & 296 & & & & \\
\hline \multirow[t]{2}{*}{$\mathrm{As}\left(\mathrm{CH}_{3}\right)_{3}$} & 568 & 223 & 583 & 239 & $100^{\circ}$ & $2 \cdot 45$ & 0.201 & [4] \\
\hline & 563 & 225 & $587 \cdot 5$ & 237 & & & & \\
\hline \multirow[t]{2}{*}{$\mathrm{Sb}\left(\mathrm{CH}_{3}\right)_{3}$} & 513 & 188 & 513 & 188 & $94^{\circ} 23^{\prime}$ & $2 \cdot 07$ & 0.139 & {$[4]$} \\
\hline & 510 & 189 & 516 & 187 & & & & \\
\hline \multirow[t]{2}{*}{$\mathrm{Bi}\left(\mathrm{CH}_{3}\right)_{3}$} & 460 & 171 & 460 & I71 & $93^{\circ} 2^{\prime}$ & 1.74 & $0 \cdot 120$ & [4] \\
\hline & 459 & 171 & 461 & 170 & & & & \\
\hline \multirow[t]{2}{*}{$\mathrm{P}(\mathrm{C} \equiv \mathrm{CH})_{3}{ }^{*}$} & 615 & 120 & 646 & 100 & $93^{\circ} 58^{\prime}$ & $3 \cdot 25$ & 0.057 & {$[16,17]$} \\
\hline & 617 & 120 & 644 & 100 & & & & \\
\hline \multirow[t]{2}{*}{$\mathrm{As}(\mathrm{C} \equiv \mathrm{CH})_{3}{ }^{*}$} & 526 & 89 & 517 & 100 & $101^{\circ} 7^{\prime}$ & 3.08 & $0 \cdot 050$ & {$[16]$} \\
\hline & 504 & 93 & 542 & 95 & & & & \\
\hline \multirow[t]{2}{*}{$\mathrm{Sb}(\mathrm{C} \equiv \mathrm{CH})_{3}$} & 477 & $(72)$ & $449 \cdot 5$ & 94 & $104^{\circ} 1^{\prime}$ & $2 \cdot 69$ & $0 \cdot 043$ & {$[\mathbf{1 6}]$} \\
\hline & 450 & 76 & 480 & 88 & & & & \\
\hline
\end{tabular}

* The striking agreement for $\mathrm{P}(\mathrm{C} \equiv \mathrm{CH})_{3}$ and the relative bad results for $\mathrm{As}(\mathrm{C} \equiv \mathrm{CH})_{3}$ and $\mathrm{Sb}(\mathrm{C}=\mathrm{CH})_{3}$ do suggest an incorrect assignment for the latter. MrLrER and LEMMON [16] say in their conolusion about the assignment that "in a few cases the symmetry species may be interchanged".

We have done so for the As- and Sb-compounds and obtained the following results:

\begin{tabular}{|c|c|c|c|c|c|c|c|c|}
\hline $\begin{array}{l}\text { Substance } \\
\mathrm{As}(\mathrm{C} \equiv \mathrm{CH})_{3}\end{array}$ & $\begin{array}{r}\omega_{1} \\
517\end{array}$ & $\begin{array}{c}\omega_{2} \\
100\end{array}$ & $\begin{array}{l}\omega_{3} \\
526\end{array}$ & $\begin{array}{c}\omega_{4} \\
89\end{array}$ & obs & $\alpha$ & $f$ & $d$ \\
\hline & 618 & 100 & 525 & 89 & eale & $92^{\circ} 28^{\prime}$ & $3 \cdot 00$ & 0.050 \\
\hline $\mathrm{Sb}(\mathrm{C} \equiv \mathrm{CH})_{3}$ & 449,5 & 94 & 477 & (72) & obs & & & \\
\hline & 472 & 89 & 458 & 75 & calc & $82^{\circ} 54^{\prime}$ & $2 \cdot 59$ & 0.041 \\
\hline
\end{tabular}

For the As-compound the results are in favour of interchanging. The assignment of the Sb-compound does not seem to fail with respect to gymmetry only.

[8] L. O. Brockway and H. O. Jenkins, $J$. Am. Chem. Soc. 58, 2036 (1936).

L. O. BrockWay and F. T. WALl, J. Am. Chem. Soc. 56, 2373 (1934).

[9] H. D. Springall and L. O. Brockway, J. Am. Chem. Soc. 60, 996 (1938).

[10] R. C. Gore, Discussions Faraday Soc. 9, 138 (1950).

[11] M. K. Wilson and S. R. Polo, J. Chem. Phys. 20, 1716 (1952).

[12] V. M. MeConaghie and H. H. NikLsen, $J$. Chem. Phys. 21, 1836 (1953).

[13] D. M. Yost and T. F. Anderson, J. Chem. Phys. 2, 624 (1934).

[14] D. M. Yost and J. E. Sherborne, J. Chem. Phys. 2, 125 (1934).

[15] M. Halmans, Spectrochim. Acta, 26, 407 (1960).

[16] F. A. MHLER and D. H. Lemmon, Spectrochim. Acta 23A, 1099 (1967).

[17] J. H. vaN DER MAAs, W. M. A. Smit, unpublished results. 


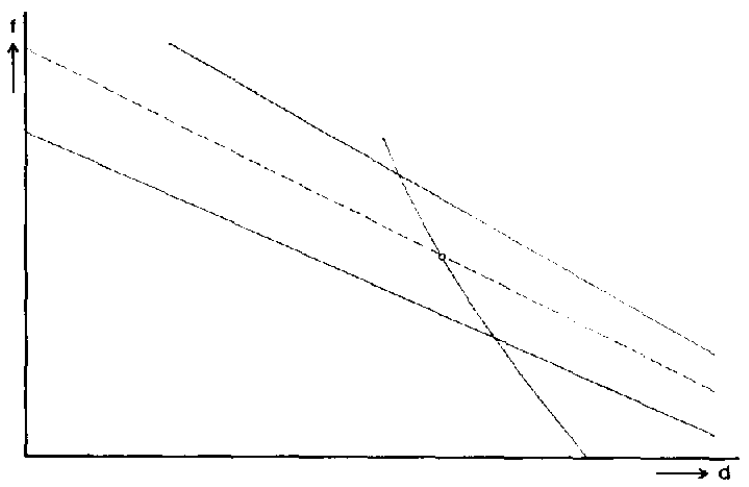

Fig. 1. $\mathrm{N}\left(\mathrm{CH}_{3}\right)_{3}$. Force constants are found from the intersection of bisectrix (broken line) and hyperbolic curve.

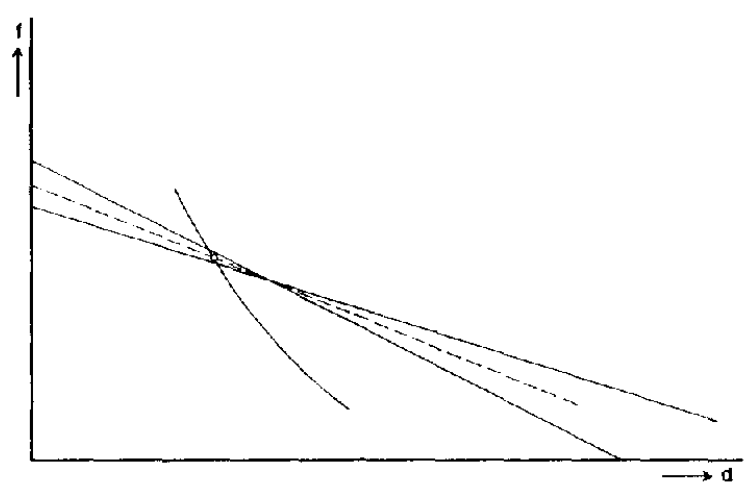

Fig. 2. $\mathrm{AsCl}_{3}$. Determination of force constants as in Fig. 1.

Table 2. Calculated force constants with apex angle values assumed or taken from references

\begin{tabular}{lccc}
\hline Substance & $\alpha$ & $f$ & $d$ \\
\hline $\mathrm{PH}_{3}$ & $93^{\circ} 50^{\prime}$ & $\mathbf{3} \cdot 10$ & $0 \cdot 323$ \\
$\mathrm{AsCl}_{3}$ & $96^{\circ}$ & $\mathbf{2} \cdot 10$ & $\mathbf{0 . 2 5 0}$ \\
$\mathrm{P}\left(\mathrm{CH}_{3}\right)_{3}$ & $103^{\circ}$ & $2 \cdot 79$ & $0 \cdot 261$ \\
$\mathrm{P}\left(\mathrm{CH}_{3}\right)_{3}$ & $100^{\circ}$ & $2 \cdot 75$ & $\mathbf{0} 266$ \\
$\mathrm{Sb}\left(\mathrm{CH}_{3}\right)_{3}$ & $98^{\circ}$ & $2 \cdot 08$ & $0 \cdot 141$ \\
$\mathrm{Sb}\left(\mathrm{CH}_{3}\right)_{3}$ & $90^{\circ}$ & $\mathbf{2 \cdot 0 6}$ & $0 \cdot 138$ \\
\hline
\end{tabular}

with these $\alpha$-values justify the procedure as followed here. The assumption of methyl and ethynyl being "point-masses" seems a rough approximation; however, the calculated frequencies agree very well with the observed ones.

A start has been made with a GF-matrix calculation of the ethynyl compounds. The $f$ and $d$ values as found here seem to be reasonable first estimates for some of the F matrix elements. 